\title{
Presence of secretory IgA antibodies to an enteric bacterial pathogen in human milk and saliva
}

Institute of Child

Health, University of Birmingham, Birmingham K A Nathavitharana A S McNeish

\section{Department of} Infection, Medical School, University of Birmingham

D Catty

C Raykundalia

Correspondence to: K A Nathavitharana Department of Paediatrics, Birmingham Heartlands Hospital NHS Trust, Bordesley Green East, Birmingham B9 5SS.

Accepted 5 October 1994

\author{
K A Nathavitharana, D Catty, C Raykundalia, A S McNeish
}

\begin{abstract}
The concept of a common mucosal immune system in man was tested by examining the concurrent presence of specific-secretory IgA (SIgA) antibodies in human milk and saliva from three groups of subjects: 64 Sri Lankan women living in Sri Lanka; 20 immigrant Asian women living in Birmingham (median duration of residence in the United Kingdom five years); and 75 Caucasian women living in Birmingham (controls). Enzyme linked immunosorbent assays (ELISA) were developed to detect enterotoxigenic Escherichia coli (ETEC) colonisation factor/1 (CFA/1) specific SIgA antibodies in milk and saliva. ETEC CFA/1 specific SIgA antibody activity was detectable in mill $(37.5 \%$ and $25 \%)$ and saliva $(42 \cdot 1 \%$ and $35 \%)$ of Sri Lankan and immigrant Asian women, respectively, but not in any of the Caucasian controls. Eighty five point two per cent of subjects who were positive had specific antibodies detectable in both milk and saliva; $5 \%$ of all Sri Lankan women and $10 \%$ of all immigrant Asian women had detectable antibody only in saliva.
\end{abstract}

These observations lend further strong support to the idea that a common mucosal immune system exists in man. The continuing presence of specific SIgA antibodies in Asian immigrants to previously encountered antigens suggests that there may be an immunological memory' in the human secretory immune system.

(Arch Dis Child 1995; 72: F102-F106)

Keywords: SIgA antibodies, $E$ coli, milk, saliva.

In developing countries enterotoxigenic Escherichia coli (ETEC) are an important cause of bacterial diarrhoea, ${ }^{1-3}$ produced by the resultant toxins. The first step in pathogenesis is the adhesion of ETEC to enterocytes, mediated by plasmid encoded colonisation factors. ${ }^{4-6}$ Most colonisation factors that have been characterised to date are fimbriae, distinct from the 'common' fimbriae present on the surface of almost all types of $E$ coli. $^{3}$ Colonisation factor antigen/1 (CFA/1) was the first to be typed. ${ }^{4}$ Toxin producing ETEC strains without plasmids encoding CFA $/ 1$ do not cause diarrhoea in human volunteers after challenge. ${ }^{5}$

Secretory IgA (SIgA), the predominant immunoglobulin in human milk, is structurally designed to fulfil a protective role in the lumen of the gut. ${ }^{7-9}$ Early workers regarded SIgA as an 'antiseptic paint' in the gut of breast fed babies. ${ }^{7}$ Previous studies have shown the presence of SIgA antibodies in human milk directed against $O$ antigens of $E$ coli, including enterotoxins. ${ }^{10-12}$ In one study of acute natural ETEC infection, Stoll et al demonstrated both a systemic and mucosal IgA antibody response to a range of ETEC antigens, including CFA $/ 1 .^{13}$

Several studies in different animal species suggest that sensitised lymphocytes originating in the gut associated and bronchus associated lymphoid tissues have a predeliction for other mucosal and exocrine glandular tissues. ${ }^{14-18}$ These observations have led to the concept of a common mucosal immune system.891920 Central to this concept is that antigen exposure at one mucosal site will lead, not only to the development of specifically sensitised lymphocytes at that site, but also to 'homing' of some of these lymphocytes, via the blood circulation, to other distant mucosal sites. There have been a few studies in man that support this concept. The appearance of specific antibodies in several mucosal secretions has been demonstrated following oral immunisation ${ }^{21-23}$ or natural gastrointestinal infection. ${ }^{13}$

If the concept of a common mucosal immune system is valid in humans the specific SIgA antibody profile of one secretion, such as saliva, might be expected to mirror closely that of another secretion, such as milk. The present study was aimed to test this hypothesis by looking for SIgA antibody with specificity to CFA/1-antigen of human ETEC in milk and saliva of individual women. The subjects were selected from three very different epidemiological backgrounds, representing varying levels of presumed natural exposure to ETEC CFA/1-antigens.

\section{Methods}

The study was approved by the research and ethical committee of Birmingham Maternity Hospital. Informed consent was obtained from all subjects. The subjects consisted of lactating women one to 310 days after delivery at term and included: Sri Lankan women (median age 25 years, range 17-37) living in Sri Lanka $(n=64)$; immigrant Asian women (median age 26 years, range 20-37) living in the United Kingdom $(n=20)$; and Caucasian women (median age 29 years, range 20-39) living in Birmingham $(n=75)$. The immigrant Asian women had been resident in Birmingham for a median duration of five years (range 14 days to 


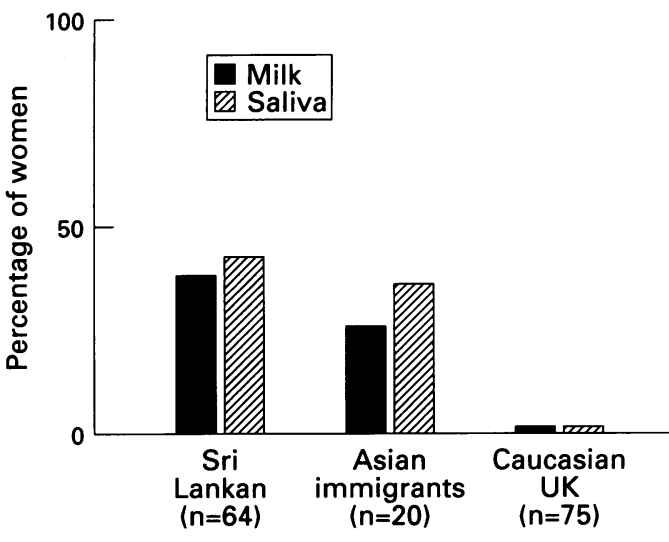

Figure 1 Percentage of women with ETEC CFA/1specific SIgA antibody detectable in their milk and saliva.

16 years), having originally arrived from countries in the Indian subcontinent (Pakistan $n=9$, India $n=8$, Bangladesh $n=2$, Sri Lanka $n=1)$. Only two of the 20 Asian women (both from India) had visited their country of origin (for two and four weeks, respectively) nine and 14 months before the present study. The Sri Lankan women were in the postnatal wards of several maternity wards in Colombo and its suburbs, or attending well baby clinics, at the time of the study. Women in the postnatal wards of the Birmingham Maternity Hospital and donor mothers of the milk bank comprised the Caucasian United Kingdom and immigrant Asian women in this study. These three subject groups represented presumed continuing high exposure, previous high exposure, and little or no exposure to ETEC CFA/1-antigen, respectively.

Details of sample collection, transport, preparation and storage have been published elsewhere. ${ }^{24}$ Briefly, specimens of milk (obtained by manual expression in over 90\%) and unstimulated saliva were collected once from each subject, at a random time point during lactation (median six, eight, and seven days, range one to 249 , one to 205 , and one to 310 days for Sri Lankan, immigrant Asian and Caucasian United Kingdom women, respectively). Sri Lankan specimens were stored frozen at $-20^{\circ} \mathrm{C}$ and transported to the United Kingdom on dry ice. Specimens from all

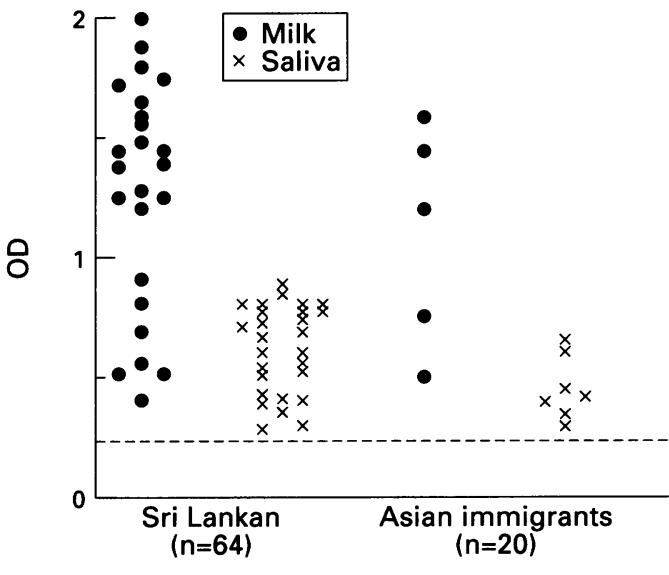

Figure 2 Optical density (OD) values produced by milk and saliva specimens with ETEC CFA/1-specific SIgA antibody (the interrupted horizontal line denotes the lower limit of detectable antibody activity). groups were centrifuged to discard the fat and the cell pellet, in the case of milk, and cell and other debris in the case of saliva, and stored at $-20^{\circ} \mathrm{C}$ until analysis.

Purified ETEC CFA/1 used in these assays (1 $\mathrm{mg} / \mathrm{ml}$ ) was kindly provided by $\operatorname{Dr} \mathrm{S}$ Knutton, Institute of Child Health, University of Birmingham. ELISA wells were coated overnight with $1 \mu \mathrm{g} / \mathrm{ml}$ of $\mathrm{CFA} / 1$. Milk or saliva (at dilutions in 1 in 10 and 1 in 2 , respectively) was added to the wells after washing and drying. The next layer was sheep IgG antibody to human secretory component (anti-human SIgA) conjugated to horseradish peroxidase in our laboratory. The reaction was developed with freshly prepared Ortho-phenylenediamine dihydrochloride as substrate. Finally, the enzyme-substrate reaction was stopped with $20 \%(\mathrm{v} / \mathrm{v})$ sulphuric acid, and the absorbance (or optical density) of the contents of the wells was measured at $492 \mathrm{~nm}$ using an ELISA plate reader. The $x+2$ SD optical density value derived from 20 control milk and of saliva specimens was $0 \cdot 15$. An optical density value of $>0.25$ (equivalent to $x+3.5 \mathrm{SD}$ ) was interpreted as indicating a positive result. The optical density values produced by undiluted individual milk and saliva specimens correlated well with the titre of specific antibody achieved by dilution analysis $\left(r_{s}=0.96 ; p<0.0001\right.$ and $0.78 ; p<0.001$, respectively; Spearman's rank correlation (data not shown)).

The SIgA antibody was ETEC-CFA/1 specific as it could not be absorbed or inhibited by crude $\mathrm{O}$ antigen or lipopolysaccharide from CFA/1 producing ETEC serotypes, but only by CFA/1 itself.

\section{Results}

Thirty seven point five per cent (24/64) of the Sri Lankan women and $25 \%(5 / 20)$ of the immigrant Asian women had detectable ETEC CFA/1 specific SIgA antibody in their milk. Forty two point one per cent (27/64) of the former and 35\% (7/20) of the latter group had detectable ETEC CFA/1 specific SIgA antibody in their saliva (fig 1). There was no significant difference in the proportion of women with specific antibodies in milk and saliva between the two study groups ( $\chi^{2}$ test). None of the Caucasian controls had ETEC CFA/1 specific SIgA antibodies in their milk or saliva.

High optical density values were produced by milk and saliva specimens from antibody positive Sri Lankan and Asian women. However, there was no significant difference in the optical density values produced by these two groups (fig 2). Of those women with ETEC CFA/1-SIgA antibody detectable in their milk or saliva, $88.8 \%(24 / 27)$ of Sri Lankan women and $71.4 \%(5 / 7)$ of their Asian counterparts had specific antibody in both secretions. All women in both study groups with specific antibody in their milk had the same antibody detectable in their saliva. However, 5\% of all Sri Lankan women and $10 \%$ of all Asian women showed specific antibody only in their saliva (fig 3). ETEC CFA/1 


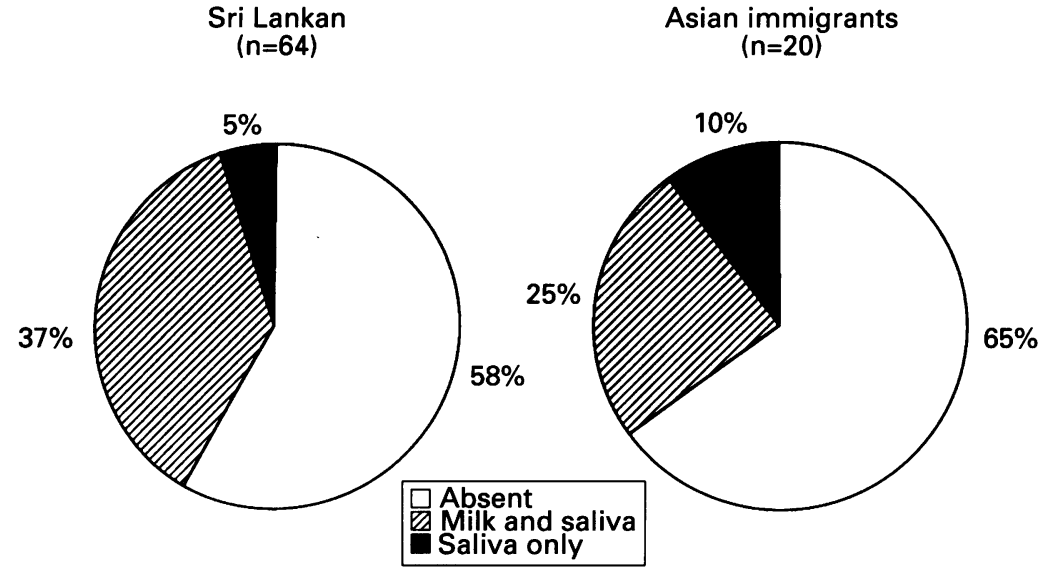

Figure 3 Concordance of ETEC CFA/1-specific SIgA antibody in milk and saliva.

specific SIgA antibody concentrations in milk and saliva from individual women showed a significant positive correlation $\left(r_{s}=0.56\right.$, $\mathrm{p}<0.01$; Spearman's rank correlation; data not shown).

\section{Discussion}

This study has demonstrated the presence of SIgA antibodies to purified ETEC CFA/1 in milk and saliva of women from the Indian subcontinent resident and non-resident in the United Kingdom. The specific antibody concentration in milk and saliva showed a significant correlation. The occurrence of specific antibodies in Sri Lankan and immigrant Asian women can be explained by the well known prevalence of ETEC in developing countries. ${ }^{1-3}$ This may have resulted in clinical or subclinical exposure of the Sri Lankan and immigrant Asian women. None of their Caucasian counterparts in the United Kingdom (where ETEC diarrhoea is rare except in travellers) had detectable specific antibody in their milk or saliva.

Because our study was cross-sectional, with only one milk sample being obtained from each mother, we can not calculate the possible quantity of specific antibody ingested over time by an individual baby of any of our subjects. Total SIgA concentration and that of specific SIgA antibodies in human milk fluctuate during lactation. ${ }^{25} 26$ Despite this fluctuation specific antibodies to bacterial antigens, such as $E$ coli heat labile antigen and Shigella $\mathrm{sp}$, persist during lactation, unlike anti-rotavirus antibody which can be difficult to detect in late lactation. ${ }^{26}$ Fifty five per cent of the milk specimens in which we demonstrated the presence of CFA/1 specific SIgA were collected within eight days of the onset of lactation (median duration of lactation in our study). Therefore, our assay is unlikely to have 'missed' potentially positive specimens from our subjects even though the individual samples were collected at a wide range of times during lactation.

A small number of women in both study groups had specific antibodies only in saliva. The specimen timing in these women was random. Specifically they were not women in the late part of lactation. The salivary glands may have encountered ETEC CFA/1 directly, without simultaneous stimulation of the Peyer's patches. This may be because, at low antigen load, the organisms and their antigens were completely denatured by gastric acid.

Few studies have examined specific antibodies in both human milk and saliva. ${ }^{1322} 2327$ Svennerholm and colleagues ${ }^{22} 23$ have demonstrated the presence of SIgA antibodies to Vibrio cholerae in the milk and saliva of Pakistani women living in Pakistan. However, the degree of concordance between specific antibody in milk and saliva of individual women is not clear from their data. We estimate $54 \%$ concordance in one study of Entamoeba histolytica specific SIgA antibodies in milk and saliva of Bangladeshi women living in Bangladesh. ${ }^{27}$

The concept of a common mucosal immune system has evolved largely from studies in animals. ${ }^{914-20}$ Previous evidence supporting the existence of a common mucosal immune system in humans is indirect and includes the known preponderance of $\operatorname{IgA} \mathrm{A}_{2}$ producing cells in salivary and lactating mammary glands compared with tonsils, peripheral lymph nodes, and the spleen, ${ }^{28} 29$ and the appearance of specific antibodies in external secretions following oral or parenteral immunisation. ${ }^{21-23} 30$ Stoll et al studied 15 patients, including lactating women, with acute natural ETEC infection, and have shown rising titres of specific IgA antibodies to a range of ETEC antigens, in serum, intestinal lavage fluid, and saliva. ${ }^{13}$ Five patients showed an antibody response in intestinal lavage fluid to CFA. Of these, three had parallel antibody responses in saliva while all four lactating women in this subgroup showed a response in their milk.

Our findings of specific mucosal antibodies to an antigen of a bacterial enteropathogen add further evidence to the suggestion that specific antibody responses in breast milk and saliva may reflect parallel responses in the gut.

Colonisation factors play an important part in the pathogenesis of ETEC diarrhoea by facilitating the adhesion of ETEC to human enterocytes. ${ }^{4-6}$ Antibodies to ETEC CFA/1 may represent an important specific defence mechanism, providing passive protection for the breast fed baby. The potential functional importance of a common mucosal immune system in affording protection to the gastrointestinal tract is supported by the appearance of specific antibody following oral immunisation $^{21-23} 30$ or clinical infection. ${ }^{132531}$ Breast feeding may also induce immune enhancement following oral immunisation, as suggested by the data of Lodiniva-Zadnikova et al, who have shown that the mucosal immune system of the newborn infant can be triggered early to produce specific antibodies against bacteria colonising the gut. ${ }^{32}$ Immune enhancement by breast feeding is also supported by studies demonstrating enhanced production of nasopharyngeal, ${ }^{33}$ urinary, ${ }^{34}{ }^{35}$ and faecal ${ }^{36} \mathrm{IgA}$ in breast fed infants.

The continuing presence of high titres of ETEC CFA/1 SIgA antibodies in immigrant Asian women in our study has not been 
reported before. This is an important observation that may suggest the existence of 'immunological memory' in the human secretory immune system. The titre of specific antibody in Asian women did not correlate with their duration of stay in the United Kingdom. The highest titre of specific antibody in this group of subjects was demonstrated in a woman who had lived in the United Kingdom for the longest period within that group (16 years). Only two of the women had visited their country of origin after arrival in the United Kingdom. In fact no CFA/1 specific SIgA antibody was demonstrable in milk or saliva from either of these two women.

We postulate several mechanisms to explain the continuing SIgA antibody response in immigrant Asian women:

(1) The persistence of ETEC might be facilitated by visits of family members to and from their native countries where ETEC is endemic. Crowded living conditions (by indigenous Caucasian standards) of many Asian families living in Birmingham may further enhance this by faecal-oral transmission. Contaminated food from sources in native countries may be another factor that merits further study.

(2) Sequestration of ETEC CFA/1 antigens in the gut-associated lymphoid tissues (GALT) might facilitate continuous stimulation of the GALT and the generation of specifically sensitised lymphocytes that migrate to other mucosal and glandular sites. This mechanism, although well recognised by workers studying 'memory' in systemic immunity, ${ }^{37}$ has received less attention in mucosal immunity. Human milk has been shown to possess $\mathrm{T}$ lymphocytes which display functional and phenotypic features of 'memory' cells. ${ }^{38}$

(3) The existence of circulating anti-idiotype antibodies that simulate critical ETEC CFA/1 epitopes could provide a perpetual stimulus for the already primed secretory immune system. Cross-reacting antigens are an unlikely explanation for our findings as the SIgA antibodies we describe were shown within the limits of our experiments to be ETEC CFA/1 specific.

The subjects in the immigrant Asian group were relatively few. A larger study will be required to extend our observations, especially to determine underlying mechanisms responsible for a continuing SIgA response several years after antigen encounter. The findings of such studies may have important implications for the development of enteric vaccines in the future.

We thank nursing and midwifery staff and colleagues at the Sorrento Maternity Hospital Milk Bank, Birmingham Maternity Hospital, and several hospitals in Colombo and Kalutara, Sri Lanka, for their help with the collection of specimens. KAN was supported by a scholarship from the Association of Commonwealth Universities.

1 Levine MM, Edelman R. Acute diarrhoeal infections in infants. Epidemiology, treatment and prospects for immunoprophylaxis. Hosp Pract 1979; 14: 89-100.

2 Stoll BJ, Glass RI, Huq MI, Khan MU, Holt JE, Banu H. Surveillance of patients attending a diarrhoeal disease hospital in Bangladesh. BMF 1982; 285: 1185-8.

3 Levine MM. Escherichia coli that cause diarrhoea. F Infect Dis 1987; 155: 377-89.

4 Evans DG, Silver RP, Evans Jr DJ, Chanse DG, Gorbach SL. Plasmid controlled colonisation factor associated with virulence in Escherichia coli enterotoxigenic for humans. Infect Immun 1975; 12: 656-67.

5 Satterwhite TK, Evans DG, DuPont HL, Evans Jr DR Role of Escherichia coli colonisation factor in acute diarrhoea. Lancet 1978; ii: 181-4.

6 Knutton S, Lloyd DR, Candy DCA, McNeish AS Adhesion of enterotoxigenic Escherichia coli to human small intestinal enterocytes. Infect Immun 1985; 48 824-31.

7 Tomasi TB, Grey HM. Structure and function of immunoglobulin A. Progr Allergy 1972; 16: 81-215.

8 Bienenstock J, Befus AD. Some thoughts on the biologic role of immunoglobulin A. Gastroenterology 1983; 84: 178-85.

9 Mestecky J, McGhee JR. Immunoglobulin A: Molecular and cellular interactions involved in IgA biosynthesis and immune response. Adv Immunol 1987; 40: 153-245.

10 Butte NF, Goldblum RM, Fehl LM, Loftin K, Smith EO Garza C, et al. Daily ingestion of immunologic compo nents in human milk during the first four months of life. Acta Paediatr Scand 1984; 73: 296-301.

11 Holmgren J, Hanson LA, Carlsson B, Lindblad BS Rahimatoola J. Neutralizing antibodies against E coli and Vibrio cholerae enterotoxins in human milk from a developing country. Scand f Immunol 1976; 5: 867-71.

12 Strollier OA, Pelley RP, Kaniecki-Green E, Klaus $M H$ Carpenter CCJ. Secretory IgA against enterotoxins in breast milk. Lancet 1976; i: 1258-61.

13 Stoll BJ, Svennerholm A-M, Gothefors L, Barua D, Huda $S$, Holmgren J. Local and systemic antibody responses to naturally acquired entertoxigenic $\mathrm{E}$ coli diarrhoea in an naturally acquired entertoxigenic E coli diarr

14 Rudzik O, Clancy RL, Perey DYE, Day RP, Bienenstock J. Repoulation with IgA-containing cells of bronchial and intestinal lamina propria after transfer of homologous Peyer's patches and bronchial lymphocytes. $\mathcal{F}$ Immuno 1975; 114: 1599-603.

15 McDermott MR, Bienenstock J. Evidence for a common mucosal immune system 1. Migration of B lymphoblasts into intestinal, respiratory and genital tissues. $\mathcal{f}$ Immunol 1979; 122: 1892-5.

16 Weiz-Carrington P, Roux ME, McWilliams M, PhillipsQuagliata JM, Lamm ME. Organ and isotype distribution of plasma cells producing specific antibody after oral of plasma cells producing specific antibody after ora immunisation: system. I Immunol 1979; 123: 1705-12.

17 Weiz-Carrington P, Grimes SR, Lamm ME. Gut-associated lymphoid tissue as a source of an IgA immune response in respiratory tissues after oral immunisation and intrabroncial challenge. Cell Immunol 1987; 106: 132-8.

18 Smith ME, Martin AF, Ford WL. Migration of lymphoblasts in the rat. Preferential localisation of DNAsynthesizing lymphocytes in particular lymph nodes and other sites. Monogr Allergy 1980; 16: 203-10

19 Tomasi TB, Zigelbaum PS. Characteristics of an immune system common to certain external secretions. $\mathcal{f}$ Exp Med 1965; 121: 101-24.

20 Bienenstock J, Befus AD. Mucosal immunology. Immunol 1980; 41: 249-70.

21 Mestecky J, McGhee JR, Arnold RR, Michalek SM, Prince $\mathrm{SJ}$, Babb JL. Selective induction of an immune response in human external secretions by ingestion of bacterial antigen. $\mathcal{f}$ Clin Invest 1978; 61: 731-7.

22 Svennerholm A-M, Holmgren J, Hanson LA, Lindblad BS Quereshi F, Rahimatoola J. Boosting of secretory IgA antibody response in man by parenteral cholera vaccine. Scand F Immunol 1977; 6: 1345-9.

23 Svennerholm A-M, Jertborn M, Gothefors L, Karim AMMM, Sack DA, Holmgren J. Mucosal antitoxic and antibacterial immunity after immunization with a combined B subunit-whole cell vaccine. $\mathcal{F}$ Infect Dis $1984 ; 149$; 884-93.

24 Nathavitharana KA, Catty D, McNeish AS. IgA antibodies in human milk: epidemiological markers of previous infecin human milk: epidemiological marke

25 Wyatt RG, Garcia B, Caceres A, Mata LJ. Immunoglobulins and antibodies in colostrum and milk of Guatemalan Mayan women. Arch Latinoam Nutr 1972 22: 629-44.

26 Cruz JR, Arevelo C. Fluctuation of specific antibodies in human milk. Acta Paediatr Scand 1985; 74: 897-903.

27 Islam A, Stroll B, Ljungstrom I, Biswas J, Nazrull H, Huld G. The prevalence of Entamoeba histolytica in lactating women and their infants in Bangladesh. Trans $R$ Soc Trop Med Hyg 1988; 82: 99-103.

28 Brandtzaeg P. The secretory immune system of lactating mammary glands compared with other exocrine glands. Ann NY Acad Sci 1983; 409: 353-83.

29 Kett K, Brandtzaeg P, Radl J, Haaijman JJ. Different subclass distribution of IgA-producing cells in human lymphoid organs and various secretory tissues. $f$ Immuno 1986; 136: 3631-5.

30 Goldblum RM, Ahlstedt S, Carlsson B, Hanson LA, Joda $\mathrm{U}$, Lindin-Janson G, et al. Antibody forming cells in human colostrum after oral immunisation. Nature 1975 257: 797-9.

31 Allardyce RA, Shearman DJC, McClelland DBL, Marwick K, Simpson AJ, Laidlaw RB. Appearance of specific colostrum antibodies after clinical infection

32 Lodinova-Zadnikova $R$, Slavikova $M$, TlaskalovaHogenova $\mathrm{H}$, Adlerberth I, Hanson LA, Wold A, et al. Hogenova $\mathrm{H}$, Adlerberth I, Hanson LA, Wold A, et al.
The antibody response in breast-fed and non breast-fed infants after artificial colonisation of the intestine with Eschrichia coli 083. Pediatr Res 1991; 29: 396-9. 
33 Stephens $S$. Development of secretory immunity in breast fed and bottle fed infants. Arch Dis Child 1986; 61: 263-9.

34 Prentice A. Breast feeding increases concentrations of IgA in infants' urine. Arch Dis Child 1987; 62: 792-5.

35 Goldblum RM, Schanler RJ, Garza C, Goldman AS Human milk feeding enhances the urinary excretion of immunologic factors in low birth weight infants. Pediatr Res 1989; 25: 184-8.
36 Koutras AK, Vigorita VJ. Fecal secretory immunoglobulin $A$ in breast milk versus formula feeding in early infancy. $\mathcal{F}$ Pediatr Gastroenterol Nutr 1989; 9: 58-61.

37 Mackay CR. Immunological Memory. Adv Immunol 1993; 53: $217-65$.

38 Bertotto A, Gerli R, Fabietti G, Crupi S, Arcangeli C, Scalise F, Vaccaro $R$. Human breast milk T-lymphocytes display the phenotype and functional characteristics of memory T cells. Eur f Immunol 1990; 20: 1877-80. 